\title{
Mobile phone radiofrequency exposure has no effect on DNA double strand breaks (DSB) in human lymphocytes
}

\author{
Elisa Danese ${ }^{1}$, Giuseppe Lippi ${ }^{1}$, Ruggero Buonocore ${ }^{2}$, Marco Benati ${ }^{1}$, Chiara Bovo ${ }^{3}$, Chiara Bonaguri ${ }^{2}$, \\ Gian Luca Salvagno ${ }^{1}$, Giorgio Brocco ${ }^{1}$, Dirk Roggenbuck ${ }^{4}$, Martina Montagnana ${ }^{1}$
}

${ }^{1}$ Section of Clinical Biochemistry, University of Verona, Verona, Italy; ${ }^{2}$ Laboratory of Clinical Chemistry and Haematology, Academic Hospital of Parma, Parma, Italy; ${ }^{3}$ Medical Direction, University Hospital of Verona, Verona, Italy; ${ }^{4}$ Faculty of Natural Sciences, Brandenburg Technical University, Senftenberg, Germany and Medipan GmbH, Dahlewitz/Berlin, Germany

Contributions: (I) Conception and design: G Lippi, D Roggenbuck, C Bovo; (II) Administrative support: None; (III) Provision of study materials or patients: E Danese, M Montagnana, GL Salvagno; (IV) Collection and assembly of data: R Buonocore, M Benati, G Brocco; (V) Data analysis and interpretation: G Lippi, E Danese, M Montagnana, C Bonaguri; (VI) Manuscript writing: All authors; (VII) Final approval of manuscript: All authors.

Correspondence to: Dr. Elisa Danese. Section of Clinical Biochemistry, University Hospital of Verona, Piazzale L.A Scuro, 1037100 - Verona, Italy. Email: elisa.danese@univr.it.

Background: The use of mobile phones has been associated with an increased risk of developing certain type of cancer, especially in long term users. Therefore, this study was aimed to investigate the potential genotoxic effect of mobile phone radiofrequency exposure on human peripheral blood mononuclear cells in vitro.

Methods: The study population consisted in 14 healthy volunteers. After collection of two whole blood samples, the former was placed in a plastic rack, $1 \mathrm{~cm}$ from the chassis of a commercial mobile phone (900 MHz carrier frequency), which was activated by a 30-min call. The second blood sample was instead maintained far from mobile phones or other RF sources. The influence of mobile phone RF on DNA integrity was assessed by analyzing $\gamma-\mathrm{H} 2 \mathrm{AX}$ foci in lymphocytes using immunofluorescence staining kit on AKLIDES.

Results: No measure of $\gamma$-H2AX foci was significantly influenced by mobile phone RF exposure, nor mobile phone exposure was associated with significant risk of genetic damages in vitro (odds ratio comprised between 0.27 and 1.00).

Conclusions: The results of this experimental study demonstrate that exposure of human lymphocytes to a conventional $900 \mathrm{MHz}$ RF emitted by a commercial mobile phone for $30 \mathrm{~min}$ does not significantly impact DNA integrity.

Keywords: Mobile phone; radiofrequency; cancer; DNA damage; lymphocytes; $\gamma$-H2AX foci

Submitted Mar 21, 2017. Accepted for publication Mar 29, 2017.

doi: $10.21037 /$ atm.2017.04.35

View this article at: http://dx.doi.org/10.21037/atm.2017.04.35

\section{Introduction}

According the recent statistics of the World Health Organization (WHO), cancer figures among the leading causes of morbidity and death around the globe, with approximately 14 million new cases and 8.2 million cancer related deaths, respectively (http://www.who.int/ mediacentre/factsheets/fs297/en/). Even more importantly, the number of new cases is expected to increase further by approximately $70 \%$ over the next 20 years, up to 22 million new cases (http://www.who.int/mediacentre/factsheets/ fs297/en/). Indeed, the risk of cancer has been greatly enhanced by modern lifestyles, through a mismatch between 
evolutionary genetics and environmental adaptations, as well as by an aging population (1).

Nevertheless, there is now consolidated evidence that most cancers are preventable, so that prudent avoidance of many well recognized risk factors would probably be effective to lower the worldwide prevalence (1).

The overall number of mobile phone users is estimated at 4.43 billion worldwide, and is expected to further increase over five billion in the next four years (http:// www.statista.com/statistics/274774/forecast-of-mobilephone-users-worldwide). This widespread use of mobile communication technology has generated deep interest in the scientific community and has stimulated wide and often controversial debates about the potential cancerogenic effects triggered by excessive exposure to radiofrequency electromagnetic fields (RFs). Accordingly, the International Agency for Research on Cancer of the WHO classifies RFs as possibly carcinogenic to humans (http://www.iarc. fr/en/media-centre/pr/2011/pdfs/pr208_E.pdf). RFs are part of the spectrum of Ultra High Frequencies (UHFs), which designates a range of electromagnetic waves with frequencies ranging from $300 \mathrm{MHz}$ to $3 \mathrm{GHz}$. In particular, those used by the global system for mobile communication (GSM) run within the $900 \mathrm{MHz}$ band. Based on their photon energy, which is less than $1.2 \mathrm{meV}$, RFs are classified as non-ionizing radiation since they are virtually unable to generate atom ionization. A particularly important issue, however, is that non-ionizing radiations may be adsorbed by biological systems, thus inducing changes in both vibrational and rotational energies of the tissues, leading to possible dissociation of molecules and dissipation of energy in the form of heat (2).

The thermal and non-thermal effects of RF have been recently explored in many biological systems (3-5), often yielding inconsistent or controversial results. Among the great deal of investigations raised in recent years, at least one evidence seemingly emerged, consisting in the fact that the use of mobile phones for 10 years or longer may increase the risk of certain types of cancer [odds ratio (OR), 1.18; 95\% confidence interval (95\% CI), 1.04-1.34], whereas this association was mostly insignificant for normal mobile phone users compared to non-users $(\mathrm{OR}=0.98$; 95\% CI, 0.89-1.07) (6). Interestingly, two other recent meta-analyses concluded that long-term ipsilateral users of mobile phone have an increased risk of glioma $(\mathrm{OR}=1.46$; 95\% CI, 1.12-1.92) (7), whereas no significant association was found with meningioma [relative risk (RR), 0.98; $95 \%$ CI, $0.75-1.28$ ] or acoustic neurinoma $(\mathrm{RR}=1.14$;
95\% CI, 0.65-1.99) in long-term mobile phone users (i.e., $\geq 10$ years) (8). Indeed, experimental evidence was brought about potential genetic damage of RFs emitted by mobile phones in human cells (9). Consistent with different groups of researches, RFs were proven to induce DNA single- and double-strand breaks (DSB), the latter being thought to be the most severe form of DNA damage since they may lead to severe losses of large fragments of DNA. However, the negative effects could only be observed in studies with small sample numbers, thus failing to provide solid genotoxicity-based mechanistic evidence (10).

The analysis of $\gamma \mathrm{H} 2 \mathrm{AX}$ foci is currently considered as the most sensitive method to detect DNA DSB, and persistent $\gamma \mathrm{H} 2 \mathrm{AX}$ foci not immediately repaired appear to be a promising biomarker for DNA damage and aging (11). After DSB occurrence, the core histone protein $\mathrm{H} 2 \mathrm{AX}$ becomes rapidly phosphorylated at serin-139 and form a so-called $\gamma \mathrm{H} 2 \mathrm{AX}$ repair focus. The immunofluorescence staining of accumulated $\gamma \mathrm{H} 2 \mathrm{AX}$ molecules by using anti- $\gamma \mathrm{H} 2 \mathrm{AX}$ antibody allow the detection of individual DSB as single nuclear focuses.

This fluorescence microscopic analysis has recently been implemented to establish fast and standardized $\gamma \mathrm{H} 2 \mathrm{AX}$ analysis and allowing rapid assessment of DNA damages in clinical practice. The platform, named AKLIDES (Medipan, Dahlewitz, Germany), permits a fully automated assessment of antinuclear immunofluorescence antibody screening (12), but also allows computational analysis of $\gamma-\mathrm{H} 2 \mathrm{AX}$ foci, which has now been successfully validated by several independent research groups (13-17). The suitability of the $\gamma \mathrm{H} 2 \mathrm{AX}$ assay to evaluate the dose-dependent formation of DSB has also been recently demonstrated for $\mathrm{X}$-ray radiation and 7 Tesla magnetic resonance image exposure (17-20). Therefore, the aim of the present study was to investigate the potential genotoxic effect of mobile phone RF exposure on human peripheral blood mononuclear cells (PBMCs) in vitro.

\section{Methods}

\section{Research design and study population}

The study population consisted in 14 healthy volunteers (mean age $43.2 \pm 10.4$ years, 11 females, 3 males), recruited from the laboratory staff. None of the study subjects had taken any medications during the week prior to the experiment. Two sequential blood samples were collected from an antecubital vein of the arm into K2-EDTA 
evacuated plastic blood tubes (Vacutest Kima s.r.l., Padova, Italy) and immediately mixed by six-time inversion. The first blood sample of each volunteer was placed in a plastic rack, $1 \mathrm{~cm}$ from the chassis of a commercial mobile phone powered by a $1,570 \mathrm{mAh}$ non-removable lithium battery. The characteristics of the mobile phone are as follows: height, $12.4 \mathrm{~cm}$; width, $5.9 \mathrm{~cm}$; thickness $0.8 \mathrm{~cm}$; carrier frequency, $900 \mathrm{MHz}$. Immediately after samples placement in the plastic rack, a call was placed on the mobile phone and the communication was manually activated for 30 min, with $3 \mathrm{G}$ and Wi-Fi connections disabled. During this period, the rack with the samples and the mobile phone was gently inverted one-time upside-down every $5 \mathrm{~min}$ for preventing sedimentation of corpuscular blood elements. After 30 min RF waves exposure, the mobile phone was removed from the plastic rack and the blood samples were left in upright position for additional $60 \mathrm{~min}$ without further mixing. The second blood sample of each volunteer was placed in another plastic rack, for $90 \mathrm{~min}$. The rack was also gently inverted one-time upside-down every $5 \mathrm{~min}$ during the first $30 \mathrm{~min}$ period (as for the samples exposed to mobile phone RF waves). The samples were then left in upright position for the remain $60 \mathrm{~min}$, without further mixing. Near contact (e.g., $<1 \mathrm{~m}$ ) of the untreated blood samples with mobile phones or other RF waves sources was accurately prevented throughout the study period. Each volunteer provided an informed consent. The study was carried out in accord with the Declaration of Helsinki, under the terms of relevant local legislation and was approved by the Institutional Review Board.

\section{$\gamma-H 2 A X$ foci analysis}

The analysis of $\gamma-\mathrm{H} 2 \mathrm{AX}$ foci in lymphocytes was performed using a $\gamma$-H2AX immunofluorescence staining kit (AKLIDES Nuk Human Lymphocyte Complete, Medipan). The $\gamma$-H2AX assay was carried out according to the manufacturer's instructions as described in details elsewhere (10). Briefly, lymphocyte-containing interfaces were collected by density gradient centrifugation at $400 \mathrm{~g}$ for $30 \mathrm{~min}$. After isolation, lymphocytes were resuspended to a final density of $1.0 \times 10^{6}$ cells $/ \mathrm{mL}$. Lymphocytes were counted by using the haematological analyser Advia 2120 (Siemens Healthcare Diagnostics, Tarrytown NY, USA) and then fixed onto microscopic slides. Slides were washed three times with PBS and then blocked with $100 \mu \mathrm{L}$ freshly prepared PBS containing 1\% BSA. Slides were incubated for 2 hours at room temperature with a primary mouse
anti-H2AX antibody, then washed two times with PBS and incubated with a secondary goat anti-mouse antibody conjugated with a fluorescent dye (Alexa Fluor 488). Nuclear counterstaining was performed with Vectashield medium containing 4',6-diamidino-2-phenylindole (DAPI).

The AKLIDES platform was used for automated image acquisition, analysis, evaluation and characterization of $\gamma-\mathrm{H} 2 \mathrm{AX}$ foci as previously described $(10,12,17)$.

For each sample a minimum of 100 cells were analysed and the follow parameters were assessed: (I) number of analysed cells; (II) number of $\gamma-\mathrm{H} 2 \mathrm{AX}$ foci; (III) $\gamma-\mathrm{H} 2 \mathrm{AX}$ foci fluorescence intensity (expressed in arbitrary units, $\mathrm{AU}$; (IV) number of cells with $\gamma$-H2AX foci; (V) percentage of affected cells; (VI) mean number of $\gamma$-H2AX foci per cell with $\gamma$-H2AX foci; (VII) mean diameter of $\gamma$-H2AX foci. The number of apoptotic cells was also reported. Given that apoptosis induces a pan-nuclear $\gamma$-H2AX phosphorylation, selected cells were scored as apoptotic, when more than $70 \%$ of the nucleus area detected in DAPI mode exceeded the threshold in the foci channel.

\section{Statistical analysis}

All data were reported as median and interquartile range (IQR). The Wilcoxon test for paired samples was used to assess the significance of difference between untreated samples and those exposed to mobile phone RF waves. Analyses were performed by GraphPad Prism 5 (Version 5.01, GraphPad Software, Inc., USA) setting the level of statistical significance at $\mathrm{P}<0.05$.

\section{Results}

A median number of 211 (IQR, 205-218) and 210 (IQR, 201-217) cells were analysed in the untreated samples and in those exposed to mobile phone RF, respectively. As shown in Table 1, no measure of $\gamma-\mathrm{H} 2 \mathrm{AX}$ foci was significantly influenced by mobile phone RF exposure. Interestingly, a marginally but not significant increase of apoptotic cells was observed. The overall number of samples which displayed increased $\gamma$-H2AX parameters and the relative OR (with 95\% CI) is shown in Table 2. In no circumstance, mobile phone exposure was associated with a significant risk of genetic damage as measured with AKLIDES Nuk Human Lymphocyte Complete (ORs comprised between 0.27 and 1.00).

A number of studies investigated the impact on genetic material of electromagnetic radiation emitted from mobile 
Table 1 Influence of 30 min mobile phone radiofrequency (RF) exposure on $\gamma$-H2AX parameters and apoptosis in human lymphocytes

\begin{tabular}{|c|c|c|c|}
\hline Parameter & Untreated & 30-min RF waves & $P$ \\
\hline$\gamma-\mathrm{H} 2 \mathrm{AX}$ foci fluorescence intensity (AU) & $74.8(44.6-83.0)$ & $66.5(55.8-78.9)$ & 0.50 \\
\hline Diameter of $\gamma-\mathrm{H} 2 \mathrm{AX}$ foci $(\mu \mathrm{m})$ & $0.4(0.3-0.4)$ & $0.3(0.2-0.5)$ & 0.29 \\
\hline Cells with $\gamma-\mathrm{H} 2 \mathrm{AX}$ foci (n) & $1.8(1.1-3.9)$ & $1.3(0.6-2.4)$ & 0.35 \\
\hline$\gamma-\mathrm{H} 2 \mathrm{AX}$ foci per cell $(\mathrm{n})$ & $0.03(0.01-0.06)$ & $0.02(0.01-0.03)$ & 0.22 \\
\hline Apoptotic cells ( $\mathrm{n}$ ) & $0.0(0.0-0.5)$ & $0.3(0.0-0.5)$ & 0.13 \\
\hline
\end{tabular}

Table 2 Number of blood sample with an increase of $\gamma$-H2AX parameters and apoptosis after 30 min mobile phone radiofrequency (RF) exposure in human lymphocytes

\begin{tabular}{|c|c|c|c|}
\hline Parameter & $\begin{array}{l}\text { No. of samples with } \\
\text { increased values }\end{array}$ & OR $(95 \% \mathrm{Cl})$ & $\mathrm{P}$ \\
\hline$\gamma-\mathrm{H} 2 \mathrm{AX}$ foci & $3 / 14$ & $0.27(0.05-1.42)$ & 0.123 \\
\hline Diameter of $\gamma-\mathrm{H} 2 \mathrm{AX}$ foci & $6 / 14$ & $0.75(0.17-3.33)$ & 0.705 \\
\hline Cells with $\gamma-\mathrm{H} 2 \mathrm{AX}$ foci & $3 / 14$ & $0.27(0.05-1.42)$ & 0.123 \\
\hline$\gamma-\mathrm{H} 2 \mathrm{AX}$ foci per cell & $4 / 14$ & $0.40(0.08-1.91)$ & 0.250 \\
\hline Apoptotic cells & $7 / 14$ & $1.00(0.23-4.40)$ & 1.000 \\
\hline
\end{tabular}

OR, odds ratio; $95 \% \mathrm{Cl}, 95 \%$ confidence interval.

phones in the last years, using heterogeneous approaches, different types of RFs and so providing controversial outcomes (21). A negative biological effect has been described on DNA integrity in the male germline, by affecting male reproductive system (22-24). Moreover, carcinogenic effects, mirrored by cell proliferation and activation of oncogene transcription, have been reported $(25,26)$.

The extent of genotoxicity has also been evaluated in different studies using different end points, including incidence of chromosomal aberrations, micronuclei or sister chromatid exchanges and single- or DSB in the DNA (9). As regards single or DSB in the DNA, studies performed in rats nearly twenty years ago described that acute exposure to high $\mathrm{RF}$ electromagnetic radiation (i.e., 2,450 MHz RF for $2 \mathrm{~h}$ ) were capable to trigger DNA breaks in brain cells $(27,28)$. In the following years, Ji et al. studied the health impact of 4-hour acute exposure to commercially available mobile phones on certain parameters such as an indicator of
DNA damage in 14 healthy adult volunteers, and concluded that this type of electromagnetic radiation was capable to trigger DNA damage in lymphocytes in vivo (29). More recently, Çam et al. analysed the short-term effects of radiofrequency radiation exposure on single-strand DNA breaks in 8 healthy human subjects before and immediately after exposure to a $900-\mathrm{MHz}$ GSM mobile phone for 15 and $30 \mathrm{~min}$ (30). Interestingly, talking on a mobile phone for up to 30 min significantly increased single-strand DNA breaks in cells of hair roots close to the phone, a damage that was found to be the highest after $30 \mathrm{~min}$ of phone use.

Contrarily, and in accord with our experimental data, some studies showed the electromagnetic radiations emitted by mobile phones may have little (if any) negative effect on DNA integrity (31-35). More specifically, Verschaeve and colleagues demonstrated that exposure for a period of 2 years, $2 \mathrm{~h}$ per day and 5 days per week [average wholebody specific absorption rates (SAR) of 0.3 or $0.9 \mathrm{~W} / \mathrm{kg}$ ], did not significantly modify DNA strand breaks in blood, liver 
and brain cells (32). Stronati et al. continuously exposed for $24 \mathrm{~h}$ blood specimens collected from 14 donors to a GSM basic $935 \mathrm{MHz}$ signal, and showed that this exposure did not induce DNA strand breaks in human lymphocytes (33). No significant changes in DNA strand breaks have also been observed by Sakuma et al. in human glioblastoma A172 cells and normal human IMR-90 fibroblasts from fetal lungs exposed to cell phone radiation for 2 and $24 \mathrm{~h}$ (31). More recently, Hou et al. (34) studied the potential adverse effects of mobile phone radiation in mouse embryonic fibroblasts after intermittent exposure $(5 \mathrm{~min}$ on $/ 10 \mathrm{~min}$ off, for various durations from 0.5 to $8 \mathrm{~h}$ ). Despite a significant increase in the levels of intracellular radical oxygen species (ROS) was observed after exposure, no significant effect was found on the number of $\gamma \mathrm{H} 2 \mathrm{AX}$. Finally, Schwarz et al. reported genotoxic effects in vitro in human fibroblasts, but not in lymphocytes, exposed to $1,950 \mathrm{MHz}$ UMTS below the SAR safety limit of $2 \mathrm{~W} / \mathrm{kg}$ (35).

\section{Discussion}

Taken together, the results of our experimental study about the exposure of human lymphocytes to conventional 900 $\mathrm{MHz}$ RF emitted by a commercial mobile phone for 30 min show little effect on DNA integrity in lymphocytes. It seems hence reasonable to suggest that such a limited time of mobile phone exposure does not carry meaningful carcinogenetic risk. Indeed, we cannot rule out that different effects may be observed after longer or excessive exposure, which is however currently discouraged by the US Food and Drug Administration (FDA) (http://www.fda.gov/ Radiation-EmittingProducts/RadiationEmittingProductsan dProcedures/HomeBusinessandEntertainment/CellPhones/ ucm 116293.htm). It is in fact suggested that the use of mobile phones should be reserved for shorter conversations and that hands-free device should be preferred due to the longer distance between the mobile phone and the user.

Indeed, this study has some limitations. Firstly, we could only investigate the in vitro effect of short-term (30 min) cell-phone exposure, whereas the cumulative effect of longer or continuative exposures may generate different effects on DNA integrity. Second, we could only evaluate the $\mathrm{y}-\mathrm{H} 2 \mathrm{AX}$ DNA repair foci in human lymphocytes, as an indicator of DNA damage. However, since it has been reported that DSB in the DNA is probably a consequence of radiation-induced changes in interaction between DNA and proteins (e.g., histones) (36), the evaluation of proteins involved in DNA repair and damage signaling, such as phosphorylated $\mathrm{H} 2 \mathrm{AX}$, is actually considered the most sensitive method to study DSB $(37,38)$.

\section{Acknowledgements}

None.

\section{Footnote}

Conflicts of Interest: The authors have no conflicts of interest to declare.

Ethical Statement: The study was carried out in accord with the Declaration of Helsinki, under the terms of relevant local legislation and was approved by the Institutional Review Board. Each volunteer provided an informed consent.

\section{References}

1. Greaves M. Cancer's Darwinian dilemma: an evolutionary tale in three acts. BMJ 2015;351:h6581.

2. Encyclopedia of Environmental Science and Engineering, Fifth Edition, Volumes One and Two Edited by James R. Pfafflin and Edward N. Ziegler CRC Press 2006 Print ISBN, 978-0-8493-9843-8 eBook ISBN, 978-1-43985186-9. Available online: http://www.crcnetbase.com/ isbn/978-0-8493-9843-8

3. Foster KR, Glaser R. Thermal mechanisms of interaction of radiofrequency energy with biological systems with relevance to exposure guidelines. Health Phys 2007;92:609-20.

4. Bohr H, Bohr J. Microwave-enhanced folding and denaturation of globular proteins. Phys Rev E Stat Phys Plasmas Fluids Relat Interdiscip Topics 2000;61:4310-4.

5. Paffi A, Apollonio F, Lovisolo GA, et al. Considerations for developing an RF exposure system, a review for in vitro biological experiments. IEEE Trans Microw Theory Tech 2010;58,2702-14.

6. Myung SK, Ju W, McDonnell DD, et al. Mobile phone use and risk of tumors: a meta-analysis. J Clin Oncol 2009;27:5565-72.

7. Gong X, Wu J, Mao Y, et al. Long-term use of mobile phone and its association with glioma: a systematic review and metaanalysis. Zhonghua Yi Xue Za Zhi 2014;94:3102-6.

8. Lagorio S, Röösli M. Mobile phone use and risk of intracranial tumors: a consistency analysis. 
Bioelectromagnetics 2014;35:79-90.

9. Verschaeve L, Juutilainen J, Lagroye I, et al. In vitro and in vivo genotoxicity of radiofrequency fields. Mutat Res 2010;705:252-68.

10. Vijayalaxmi, Prihoda TJ. Genetic damage in human cells exposed to non-ionizing radiofrequency fields: a metaanalysis of the data from 88 publications (1990-2011). Mutat Res 2012;749:1-16.

11. Siddiqui MS, François M, Fenech MF, et al.Persistent $\gamma \mathrm{H} 2 \mathrm{AX}$ : A promising molecular marker of DNA damage and aging. Mutat Res Rev Mutat Res 2015;766:1-19.

12. Bizzaro N, Antico A, Platzgummer S, et al. Automated antinuclear immunofluorescence antibody screening: a comparative study of six computer-aided diagnostic systems. Autoimmun Rev 2014;13:292-8.

13. Willitzki A, Hiemann R, Peters V, et al. New platform technology for comprehensive serological diagnostics of autoimmune diseases. Clin Dev Immunol 2012;2012:284740.

14. Willitzki A, Lorenz S, Hiemann R, et al. Fully automated analysis of chemically induced $\gamma \mathrm{H} 2 \mathrm{AX}$ foci in human peripheral blood mononuclear cells by indirect immunofluorescence. Cytometry A 2013;83:1017-26.

15. Ivashkevich AN, Martin OA, Smith AJ, et al. $\gamma \mathrm{H} 2 \mathrm{AX}$ foci as a measure of DNA damage: a computational approach to automatic analysis. Mutat Res 2011;711:49-60.

16. Hiemann R, Büttner T, Krieger T, et al. Challenges of automated screening and differentiation of non-organ specific autoantibodies on HEp-2 cells. Autoimmun Rev 2009;9:17-22.

17. Runge R, Hiemann R, Wendisch M, et al. Fully automated interpretation of ionizing radiation-induced $\gamma \mathrm{H} 2 \mathrm{AX}$ foci by the novel pattern recognition system AKLIDES®. Int J Radiat Biol 2012;88:439-47.

18. Schwab SA, Brand M, Schlude IK, et al. X-ray induced formation of $\gamma-\mathrm{H} 2 \mathrm{AX}$ foci after full-field digital mammography and digital breast-tomosynthesis. PLoS One 2013;8:e70660.

19. Rothkamm K, Balroop S, Shekhdar J, et al. Leukocyte DNA damage after multi-detector row CT: a quantitative biomarker of low-level radiation exposure. Radiology 2007;242:244-51.

20. Reddig A, Fatahi M, Friebe B, et al. Analysis of DNA Double-Strand Breaks and Cytotoxicity after 7 Tesla Magnetic Resonance Imaging of Isolated Human Lymphocytes. PLoS One 2015;10:e0132702.

21. Moulder JE, Foster KR, Erdreich LS, et al. Mobile phones, mobile phone base stations and cancer: a review.
Int J Radiat Biol 2005;81:189-203.

22. Agarwal A, Deepinder F, Sharma RK, et al. Effect of cell phone usage on semen analysis in men attending infertility clinic: an observational study. Fertil Steril 2008;89:124-8.

23. Aitken RJ, Bennetts LE, Sawyer D, et al. Impact of radio frequency electromagnetic radiation on DNA integrity in the male germline. Int J Androl 2005;28:171-9.

24. Zalata A, El-Samanoudy AZ, Shaalan D, et al. In vitro effect of cell phone radiation on motility, DNA fragmentation and clusterin gene expression in human sperm. Int J Fertil Steril 2015;9:129-36.

25. Goswami PC, Albee LD, Parsian AJ, et al. Proto-oncogene mRNA levels and activities of multiple transcription factors in $\mathrm{C} 3 \mathrm{H} 10 \mathrm{~T} 1 / 2$ murine embryonic fibroblasts exposed to 835.62 and $847.74 \mathrm{MHz}$ cellular phone communication frequency radiation. Radiat Res 1999;151:300-9.

26. Marinelli F, La Sala D, Cicciotti G, et al. Exposure to 900 $\mathrm{MHz}$ electromagnetic field induces an unbalance between pro-apoptotic and pro-survival signals in T-lymphoblastoid leukemia CCRF-CEM cells. J Cell Physiol 2004;198:324-32.

27. Lai H, Singh NP. Acute low-intensity microwave exposure increases DNA single-strand breaks in rat brain cells. Bioelectromagnetics 1995;16:207-10.

28. Lai H, Singh NP. Single- and double-strand DNA breaks in rat brain cells after acute exposure to radiofrequency electromagnetic radiation. Int J Radiat Biol 1996;69:513-21.

29. Ji S, Oh E, Sul D, et al. DNA Damage of Lymphocytes in Volunteers after 4 hours Use of Mobile Phone. J Prev Med Public Health 2004;37:373-80.

30. Çam ST, Seyhan N. Single-strand DNA breaks in human hair root cells exposed to mobile phone radiation. Int J Radiat Biol 2012;88:420-4.

31. Sakuma N, Komatsubara Y, Takeda H, et al. DNA strand breaks are not induced in human cells exposed to $2.1425 \mathrm{GHz}$ band CW and W-CDMA modulated radiofrequency fields allocated to mobile radio base stations. Bioelectromagnetics 2006;27:51-7.

32. Verschaeve L, Heikkinen P, Verheyen G, et al. Investigation of co-genotoxic effects of radiofrequency electromagnetic fields in vivo. Investigation of cogenotoxic effects of radiofrequency electromagnetic fields in vivo. Radiat Res 2006;165:598-607.

33. Stronati L, Testa A, Moquet J, et al. $935 \mathrm{MHz}$ cellular phone radiation. An in vitro study of genotoxicity in human lymphocytes. Int J Radiat Biol 2006;82:339-46.

34. Hou Q, Wang M, Wu S, et al. Oxidative changes and apoptosis induced by $1800-\mathrm{MHz}$ electromagnetic radiation in NIH/3T3 cells. Electromagn Biol Med 2015;34:85-92. 
35. Schwarz C, Kratochvil E, Pilger A, et al. Radiofrequency electromagnetic fields (UMTS, 1,950 MHz) induce genotoxic effects in vitro in human fibroblasts but not in lymphocytes. Int Arch Occup Environ Health 2008;81:755-67.

36. Belyaev IY, Eriksson S, Nygren J, et al. Effects of ethidium bromide on DNA loop organisation in human lymphocytes measured by anomalous viscosity time dependence and single cell gel electrophoresis. Biochim Biophys Acta

Cite this article as: Danese E, Lippi G, Buonocore R, Benati M, Bovo C, Bonaguri C, Salvagno GL, Brocco G, Roggenbuck D, Montagnana M. Mobile phone radiofrequency exposure has no effect on DNA double strand breaks (DSB) in human lymphocytes. Ann Transl Med 2017;5(13):272. doi: 10.21037/ atm.2017.04.35
1999;1428:348-56.

37. Belyaev IY, Markovà E, Hillert L, et al. Microwaves from UMTS/GSM mobile phones induce long-lasting inhibition of 53BP1/gamma-H2AX DNA repair foci in human lymphocytes. Bioelectromagnetics 2009;30:129-41.

38. Rogakou EP, Boon C, Redon C, et al. Megabase chromatin domains involved in DNA double-strand breaks in vivo. J Cell Biol 1999;146:905-16. 